\title{
Monitoring of the ratio of nitrate to sulphate in size-segregated submicron aerosol in the Netherlands
}

\author{
H.M. ten Brink \\ R.P. Otjes \\ P.A.C. Jongejan \\ G.P.A. Kos
}

Published in Atmospheric Research 92 (2009) 270-276 
Provided for non-commercial research and education use. Not for reproduction, distribution or commercial use.

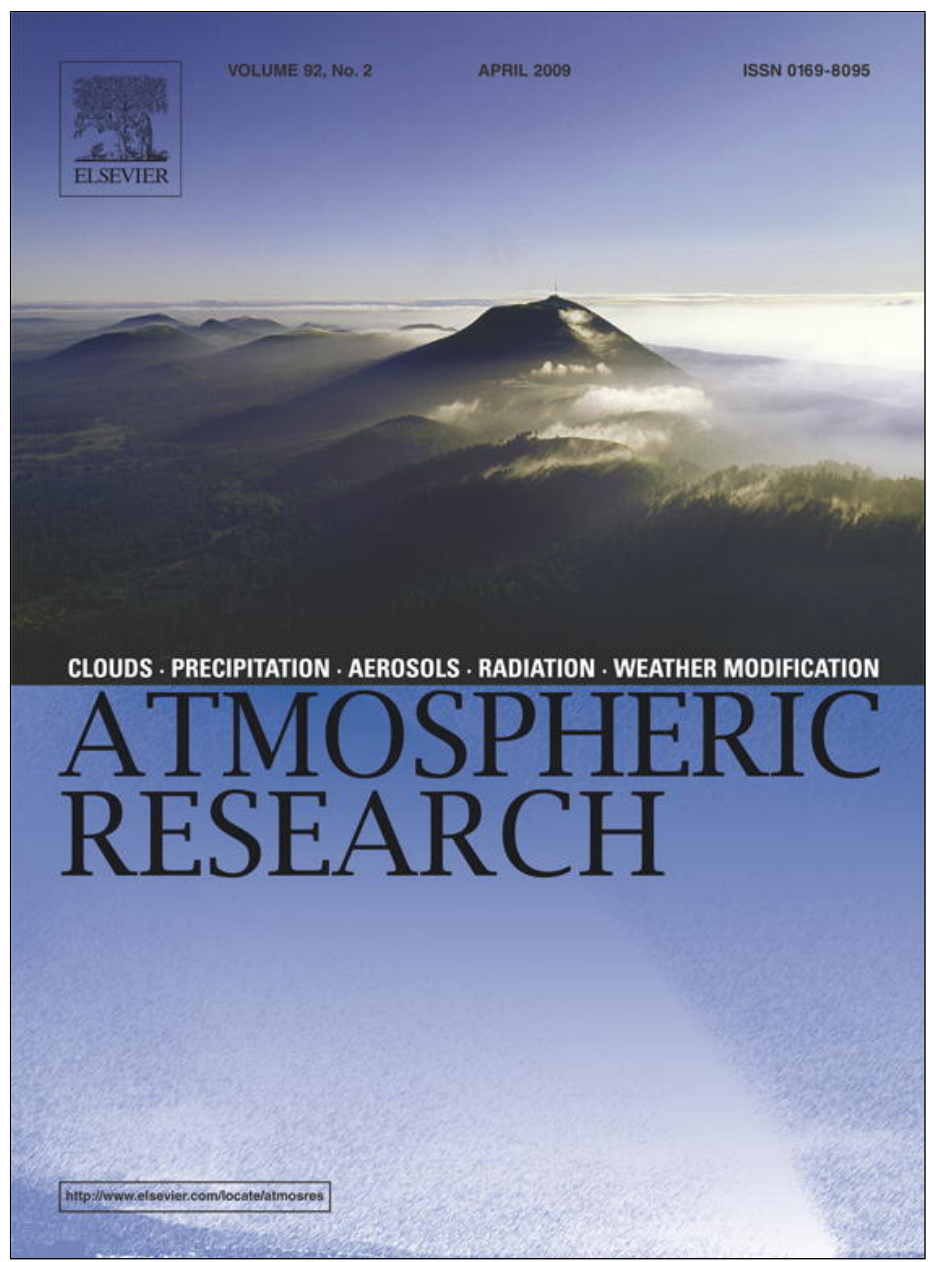

This article appeared in a journal published by Elsevier. The attached copy is furnished to the author for internal non-commercial research and education use, including for instruction at the authors institution and sharing with colleagues.

Other uses, including reproduction and distribution, or selling or licensing copies, or posting to personal, institutional or third party websites are prohibited.

In most cases authors are permitted to post their version of the article (e.g. in Word or Tex form) to their personal website or institutional repository. Authors requiring further information regarding Elsevier's archiving and manuscript policies are encouraged to visit:

http://www.elsevier.com/copyright 


\title{
Monitoring of the ratio of nitrate to sulphate in size-segregated submicron aerosol in the Netherlands
}

\author{
Harry ten Brink* ${ }^{*}$, Rene Otjes, Piet Jongejan, Gerard Kos \\ Energy research Centre of the Netherlands (ECN), Petten, The Netherlands
}

\section{A R T I C L E I N F O}

\section{Article history:}

Received 24 August 2007

Received in revised form 14 November 2008

Accepted 3 December 2008

\section{Keywords:}

Nitrate

CCN

Sulphate

Ultrafines

\begin{abstract}
A B S T R A C T
We followed the concentration of nitrate and sulphate in size-segregated aerosol. In the evaluation we focused on the data in the smallest aerosol, that is, in particles with an (aerodynamic) diameter smaller than $0.18 \mu \mathrm{m}$. The average ratio of nitrate to sulphate in this range was 0.6. The nitrate was present in the form of the semi-volatile ammonium nitrate, which was representatively measured with a prototype "MARGA-sizer". This instrument works as follows. Aerosol is grown to droplets that are easily collected; these then drain to on-line wet-chemical analysis systems. The size-classification of the aerosol, prior to collection, is accomplished with impactors. There is also a parallel line in which the aerosol is removed with a filter. Data stemming from this line serve as the in-situ field blanks. The instrument is fully automated and, with a measuring cycle of $2 \mathrm{~h}$, provides a semi-continuous data set.

The monitoring campaign occurred at the CESAR-site of Cabauw, at the highest observation level of the meteo-tower $(200 \mathrm{~m})$. The campaign took place in the summer and a diurnal variation of the semi-volatile ammonium nitrate had been expected, with lower concentrations during the warm daytime hours, especially for the smallest aerosol fraction. Such a diurnal cycle was not observed. A first explanation is that the ammonium nitrate is stabilised by the high levels of ammonia-gas, even at the elevated temperatures occurring during the campaign. The issue, however, is more complex because of horizontal and vertical transport, which calls for analysis with detailed atmospheric chemical modelling.
\end{abstract}

(c) 2008 Elsevier B.V. All rights reserved.

\section{Introduction}

There is quite an interest in size-segregated data for the major components in aerosol. One of the reasons is the importance of aerosol in the radiative forcing of climate, which is highly sensitive to the size of the aerosol (Penner et al., 2001; Forster et al., 2007). In the particles that are most active the concentration of sulphate is high, but its levels are rapidly declining in our region (Arends et al., 1997). This would imply that the aerosol forcing may become an insignificant factor here.

The assumption of a decrease in aerosol radiative forcing with the decline in sulphate might be premature, because sulphate is not the only important component. The role of nitrate

\footnotetext{
* Corresponding author. Westerduinweg 3, Bdg 04, 1755 ZG, Petten, The Netherlands. Tel.: +31 224564568; fax: +31 224568488.

E-mail address: tenbrink@ecn.nl (H. ten Brink).
}

in the so-called direct radiative forcing effect (Forster et al., 2007) is recognised, but its contribution to the even more important "Indirect Aerosol Effect" has not been addressed yet. The Indirect Aerosol Effect is the phenomenon that anthropogenic aerosol particles serve as extra cloud condensation nuclei, as described in detail in the above mentioned references. Nitrate has similar hygroscopic properties as sulphate and would thus be a good agent for cloud condensation. A first requirement is that it must be present in the size class of the aerosols that are active in cloud formation, the Cloud Condensation Nuclei (CCN).

For the clouds in which the Indirect Aerosol Effect occurs the diameter of the $\mathrm{CCN}$ is roughly in the range of 0.1 to $0.2 \mu \mathrm{m}$, see e.g., Khlystov et al. (1997a), Khlystov (1998), Martin et al. (1994) and Raga and Jonas (1993). There is now ample proof of the occurrence of high concentrations of nitrate in this sizerange in Europe. To cite the most prominent in this area: Putaud et al. (2004), Matta et al. (2003), Sellegri et al. (2003a,b) and 
Herrmann et al. (2006). However, the published amounts might be even higher in view of losses that can occur during sampling.

Loss of nitrate is due to the form in which the submicron compound is present, viz., as the semi-volatile ammonium nitrate. Size-classified collection occurs with cascade-impactors and evaporation of collected nitrate was clearly demonstrated in the work of Chang et al. (2001) and ten Brink et al. (1997). Enhanced evaporation of nitrate in the smallest particles is expected, because these are often sampled on a filter for which losses can be high (Chang et al., 2001). In addition, stripping of nitric acid occurs by deposition to substrates and wall surface during passage through the impactor-train (Bondietti and Papastefanou, 1989). This enhances the evaporation of the ammonium nitrate at the end of the train, at which site the smallest particles are collected. The foregoing illustrates the need for a system with which nitrate in the smallest aerosol particles is representatively collected.

As discussed above, sulphate is considered to be the dominant forcing agent and to put the importance of nitrate in perspective we compare its concentration with that of sulphate. Obtaining information on sulphate was rather simple, because the monitor also measures this compound. In the following we describe the instrument, its application and the first results obtained in a measuring campaign. The monitoring provided 2-hr data, from which the diurnal variation of the components could be evaluated.

Ideally the composition of the $\mathrm{CCN}$, the aerosol in the above mentioned size-range of 0.1-0.2 $\mu \mathrm{m}$, should have been monitored. However, use was made of an existing size-segregator at an aerodynamic diameter of $0.18 \mu \mathrm{m}$. Size-segregation at $0.1 \mu \mathrm{m}$ was not feasible, because of operational complications described in Section 2.1.2 below. Hence the fraction of interest is operationally defined here as the regime of aerosol smaller than $0.18 \mu \mathrm{m}$ (aerodynamic diameter) and termed "CCN-range".

\section{Experimental}

\subsection{Instrumentation}

\subsubsection{On-line monitor "MARGA"}

The measurement of the concentration of nitrate and sulphate in the size-class of interest were made with an extension to the home-built "MARGA". The MARGA was specifically designed to representatively sample the semi-volatile ammonium nitrate (Slanina et al., 2001). The working principle is the growth of the aerosol to droplets in a turbulent cloud chamber. To this purpose steam is injected into the sampling air and rapid turbulent mixing leads to large supersaturations with activation of aerosol particles with a diameter down to $20 \mathrm{~nm}$. The droplets that are formed are so large that they can be collected with a cyclone. Water-soluble aerosol constituents dissolve into the water that drains down from the collector.

The drain from the cyclone is fed to wet-chemical analysers, which are in principle the same as used for analysis of manually collected aerosol. This means Ion Chromatography for the anions and a special detection system for ammonium that was developed in-house (Slanina et al., 2001).

An essential part of the system is the gas-denuder that removes gases like nitric acid and ammonia that would otherwise be collected in the steam sampler and counted as if it were part of the aerosol. The denuder also allows measurement of the gases by analysing the drain from the denuder and the acronym MARGA, Monitor for Measuring AeRosol and Gases, derives from the possibility to measure aerosol and gas components simultaneously. Full details on the MARGA are given elsewhere (Trebs et al., 2004). Incidentally, the instrument was coined WAD/SJAC at the time; this is the acronym for Wet Annular Denuder/Steam Jet Aerosol Collector.

\subsubsection{Size-classification}

Pre-selectors are used to classify the aerosol size-classes before collection and analysis. Impactor-stages, taken, from a commercial MOI (Micro-Orifice Impactor, MSP corporation, Shoreview, MN, USA), were used to this purpose. We dissembled the multi-stage unit and made a special housing for a single stage. The impactor with the lowest cut-off diameter was that of $0.18 \mu \mathrm{m}$. Ideally also an impactor with a cut-off diameter of $0.1 \mu \mathrm{m}$ should have been used so as to obtain a more detailed classification of the aerosol in the most relevant range of 0.1 to $0.2 \mu \mathrm{m}$. However this was not tried (yet) for fear that the high pressure drop over the associated impactor would lead to problems with the rotating gas-denuder to be discussed below. This fear was based on earlier unsuccessful attempts to use a low-pressure impactor for size-classification (Mikuska et al., 1997). Another issue was that it was calculated that the detectors would not be sufficiently sensitive to measure the trace amounts in the ultrafine aerosols.

The basic instrumentation and performance tests were described before (ten Brink et al., 2007). It was shown there that the cut-off characteristics of the impactor in its standalone did not substantially differ from that in the cascadetrain. Emphasis in the present study was on optimal detection of the amount of material that passes the impactor with cutoff diameter, at $0.18 \mu \mathrm{m}$, and this asked for special leak-tight connections. As a check the pressure drop over the impactor was continuously followed in the monitoring campaign described below.

In order to protect the impactors from clogging by deposition of an excess amount of coarse particles, they were preceded by an impactor with a cut-off of at a larger diameter. For the impactor with cut-off diameter of 0.18 diameter the protecting impactor was that with a cut-off at $1.8 \mu \mathrm{m}$ diameter. The amount of aerosol-material sampled in the channel with this impactor is small. This means that the value of the blank that has to be subtracted from the measured value is critical. The blank is the signal that is obtained in the absence of an aerosol sample.

In the present instrument an easy provision was made to determine the blank value, by the addition of an extra line with a filter. This filter removes all aerosol. The value obtained in the analysis step of this line provides the "field" blank. It is obtained in every measuring cycle and its value is subtracted from that in the measuring lines.

For automated measurements the inlet sample flow is successively directed to one of the parallel lines of the preseparator manifold lines (Fig. 1). This is accomplished with automated large bore valves (type EA, End-Armaturen $\mathrm{GmbH}$, Bad Oeynhausen, Germany; bore size 1/2 inch). There is no measurable loss of aerosol in the valves. An in-house provision was made for automatic switching of the valve such that successively one of the sampling lines is opened while the 


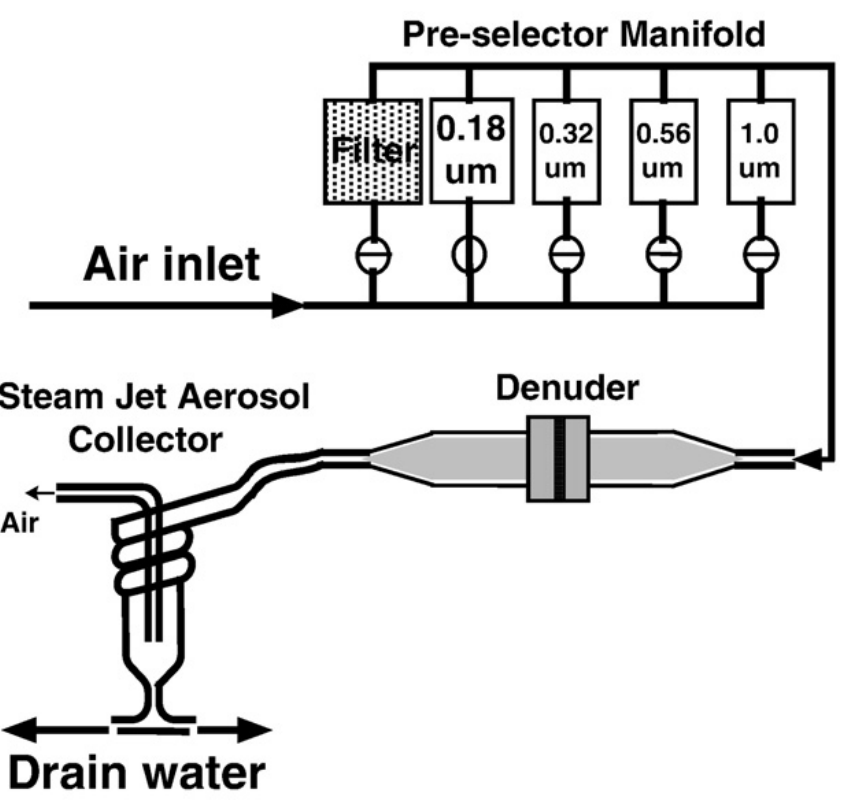

Fig. 1. Sketch of the instrument for measuring the concentration of nitrate and sulphate in size-segregated aerosol. The selection of the particles is accomplished by directing the inlet-flow, upper arrow, via the various lines in the manifold with impactors of the indicated aerodynamic cut-off diameter. Subsequently, the sampling flow passes the gas-denuder for removal of interfering gases to the steam jet aerosol collector; the drain from the cyclone-collector is fed to wet-chemical analysers. The blank-line is that indicated by "filter" to the left in the manifold.

others are closed. Each line samples for a period of $20 \mathrm{~min}$. A measuring cycle thus takes $2 \mathrm{~h}$. This includes measurement of the gases taken up in de gas-denuder that is described in the next section.

\subsubsection{Gas-denuder}

Essential, in the context of the collection of the semivolatile ammonium nitrate, is the removal of the watersoluble gases. These compounds, ammonia, nitric and sulphur dioxide would otherwise be sampled in the steam collector and would be counted as the respective aerosol constituent. To prevent the gases from entering the aerosol collector a gasdenuder is used. The denuder is between the pre-selector manifold and aerosol-collector.

The denuder operates in a continuous way because water is used as the absorption medium and the absorption fluid is refreshed. The advantage is that the denuder has unlimited capacity unlike a solid-state denuder that becomes saturated and has to be frequently renewed.

The denuder is not at the entrance of the system because it works as a humidifier, which would lead to undesired growth of the particles. An other advantage of having the denuder after the impactor and filter is that it also removes gases that may originate from ammonium nitrate collected in the impactors over a longer period and evaporating later. This could especially occur in situations in which ammonium nitrate is sampled at low temperatures, for instance at night, and evaporating from the impactor plates under the warmer daytime conditions. This could specifically be interference for the small amounts measured in the smallest aerosol-fraction.

As mentioned above, ammonium nitrate is semi-volatile and it might be questioned how much of it evaporates during passage of the aerosol through the denuder or at the high temperatures occurring in the steam collector. Such evaporation is not significant for total ammonium nitrate (Slanina et al., 2001), but could be important for the smallest aerosols, which most easily volatilise. It can be argued that this is not the case. We demonstrated that the characteristic time for evaporation of pure ammonium nitrate with a size of $0.1 \mu \mathrm{m}$ is in the order of $10 \mathrm{~s}$ (Khlystov et al., 1997b). Moreover, at the high RH in the wet denuder, evaporation is much further suppressed. Summarising, the characteristic time for evaporation of $10 \mathrm{~s}$ is much longer than the transit time through the denuder, which is $0.16 \mathrm{~s}$ and volatilisation of ammonium nitrate in the denuder is thus negligible.

A last issue is the behaviour of the semi-volatile ammonium nitrate in the steam collector. The introduction of stream increases the temperature and this could lead to volatilisation. However, as soon as the air mixes with the steam the temperatures are lowered and furthermore the decomposition products are so soluble that they even fully dissolve in the water condensing on the walls, as was experimentally verified.

The new instrumentation also measures the concentration of sulphate and chloride. Ammonium, which is the usual counter-ion of submicron nitrate and sulphate, is also determined. This is done with a separate detector as mentioned above. The new instrument is known as "MARGA-sizer".

\subsubsection{Performance of the MARGA-sizer in the measuring campaign}

The MARGA-sizer was taken to the field and a frequency for maintenance of once a week was foreseen; however, it appeared that extra servicing was required due to the high temperatures inside the tower. This came quite unexpectedly, because the outside temperatures were moderate with maxima of less than $30^{\circ} \mathrm{C}$; however, temperature inside the tower could exceed $40{ }^{\circ} \mathrm{C}$, which gave rise to malfunctioning of the electronics. Another issue is the possible heating of air and aerosol in the sampling line and associated evaporation of ammonium nitrate.

The sampling line is of copper and extends some distance inside the tower. This part must have warmed up because of the higher temperatures inside. It implies that also the sampling air increased in temperature, which must have induced evaporation of the semi-volatile ammonium nitrate. However, the transit time in the line is short (of the order of one second) and evaporation of ammonium nitrate should thus be minimal. Moreover, in case of some volatile loss the concentrations of ammonium nitrate as measured are minimum values, especially those in the smallest particles that most easily volatilise.

The high temperatures also affected the wet-denuder. Circulation of solution was often not at the optimum value required for analysis of the drain and sometimes the denuder dried out. It was feared that the drying would decrease the efficiency of the denuder, but the denuder performance remained high as demonstrated by the efficient removal of the gases, including ammonia and sulphur dioxide (ten Brink et al., 2007).

\subsection{Campaign}

The campaign to monitor the concentrations of nitrate and sulphate in the CCN-size range took place at the CESAR-site 
of Cabauw, at the highest observation level of the meteo-tower (200 m). An elevated sampling location was used, because the concentration of the semi-volatile ammonium nitrate is affected by the concentration of ammonia. This component can have a quite steep vertical gradient in the Netherlands because of its emission by local surface sources (Allen et al., 1989). The concentration of ammonium nitrate depends on that of ammonia because of the equilibrium that exists between ammonium nitrate in the aerosol-phase and the dissociation products of which ammonia is one. The effect of localised emissions of ammonia is suppressed at the top of the tower and hence a more representative value for the regional concentration of ammonium nitrate at cloud level should be obtained.

The other dissociation product is nitric acid for which a vertical gradient should be absent, because it is produced in the atmosphere in a rather slow formation process. It should therefore be quite equally distributed in the planetary boundary layer.

The campaign to measure ammonium nitrate in the CCNrange was undertaken in the summer of 2002, lasting from June 21 to August 19. Servicing/maintenance of the instrumentation was scheduled at a frequency of once a week. Performance of the instrument with respect to flow and pressuredrop over the impactors could be checked at the institute and, in case of apparent malfunctioning, next-day repair could take place.

\section{Results and discussion}

The measuring campaign was quite successful, as shown in an overall data-coverage of $65 \%$. Complications associated with the high temperatures inside the tower, as discussed above, were the main reason for absence of more data. Before turning to the results of the measurement we first discuss the detection limit, which is determined by the blanks that are obtained in the sampling line with aerosol-free air. As men- tioned this blank is obtained in every measuring cycle of two hours.

Fig. 2 is indicative of a possible correlation of blank value and the amount of nitrate in the associated impactor line. We made a more systematic analysis of this correlation by plotting the paired signals of blank and sample per measuring cycle, see Fig. 3. Indeed, the plot in Fig. 3 is indicative of a positive correlation. A full evaluation of the plot is complicated, because the absolute value of the blank may change from week to week, as discussed below. Such systematic blank variations hamper a good analysis of the scatter plot.

There was a long-term change in the blank value, in the sense that blank values could differ between two weekly zero-checks of the analysis system. This was quite evident in an instance when a high blank for the compound chloride was observed, while the average blank for this component is low. We assume that this event was connected with a slightly contaminated batch of eluent for the IC-analysis. Such a systematic bias in the blank signal, however, is a lesser concern as long as the variation is small. Moreover, a high absolute blank is not problematic, because its value is subtracted from the value of the associated sample.

The other, more problematic, issue was the presence of an occasional spurious spike in the blank signals, as can already be visually observed in both Figs. 2 and 3. This typically occurred for nitrate. We screened for these events and rejected the value when it was larger than the average value of the blank for that week plus three times the Standard Deviation. Instead of the measured blank we used the average value of the blank in the previous and next measuring cycle. With this procedure a new standard deviation in the variation in the blank is obtained of $0.05 \mu \mathrm{g} \mathrm{m}^{-3}$. This translates into a lower limit of detection (LOD) of $0.15 \mu \mathrm{g} \mathrm{m}^{-3}$.

The LOD compares favourably with the average concentration of nitrate in the CCN-range, as seen in Fig. 2. The data for this range were also screened for outliers, viz., as follows. We rejected those values for which the concentration in the

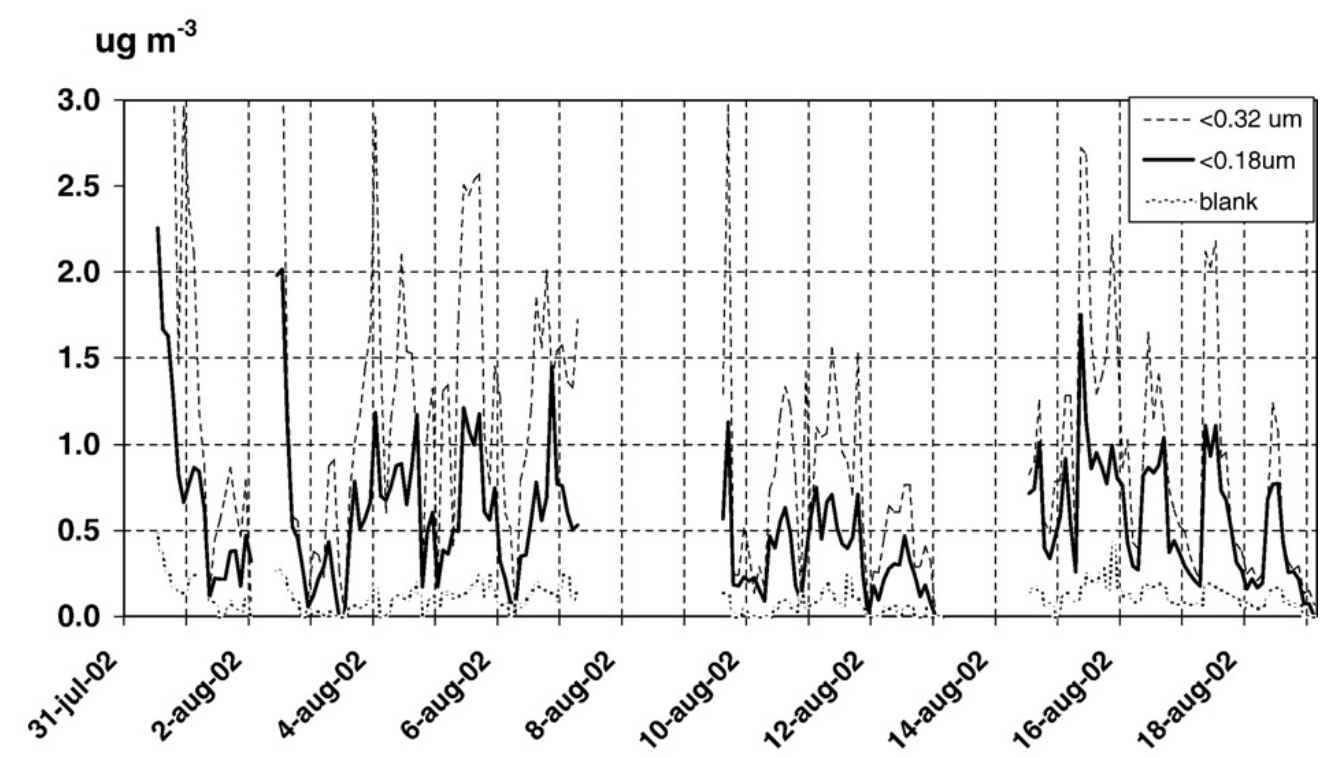

Fig. 2. Time series of the concentration of nitrate in the CCN-range (aerosol smaller than $0.18 \mu$ m aerodynamic diameter). Results are shown of a monitoring campaign at the $200 \mathrm{~m}$ level of the meteo-tower of Cabauw in the Netherlands in the indicated period. The time-variation of the "blank" is also shown, as well as the concentration of nitrate in particles smaller than $0.32 \mu \mathrm{m}$. 


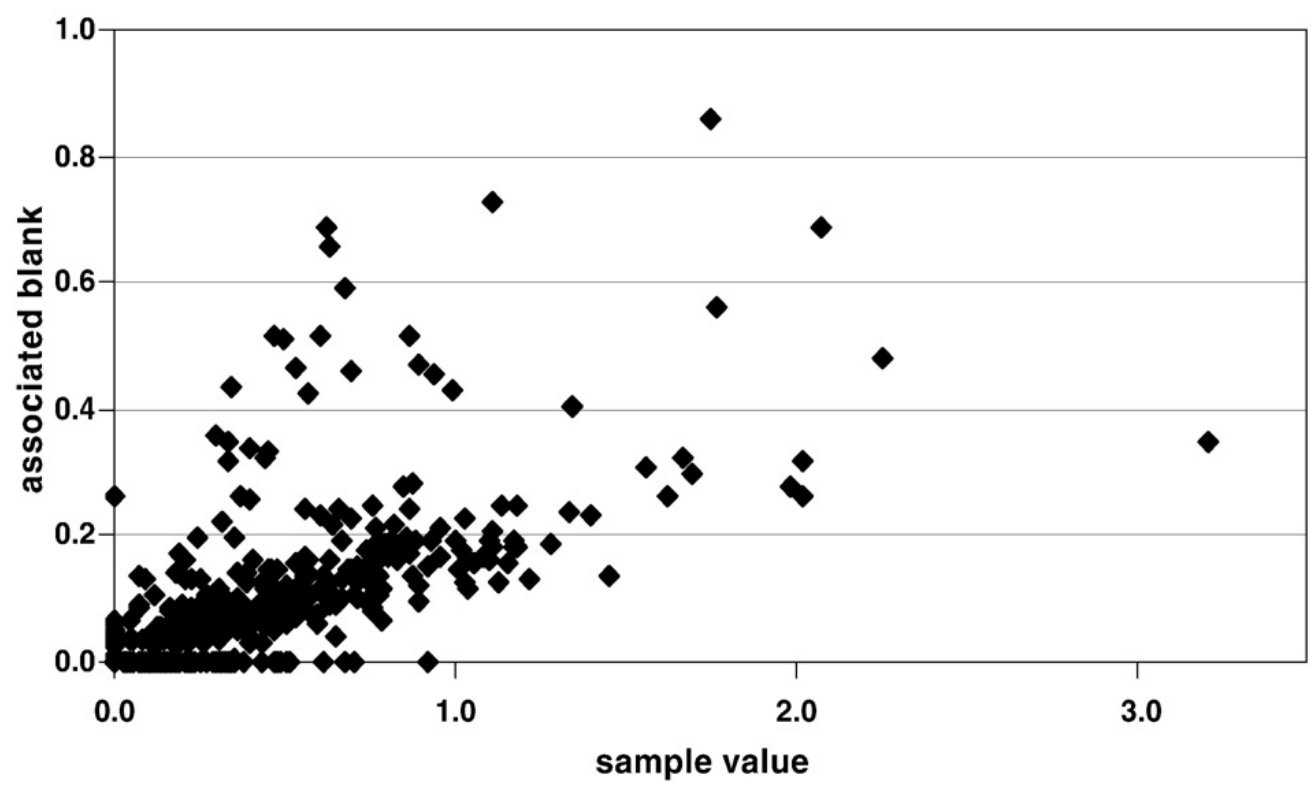

Fig. 3. Scatter plot of the paired value of the blank and the value of the associated sample for nitrate in aerosol smaller than $0.18 \mu \mathrm{m}$ in diameter; concentrations in $\mu \mathrm{g} \mathrm{m} \mathrm{m}^{-3}$.

CCN-range was significantly higher than those in a line with an impactor with a cut-off diameter of $0.32 \mu \mathrm{m}$, see Fig. 2. Significant in this context means that the difference was more than twice the value of the LOD. This led to a data coverage of a little over $60 \%$. With the new data-evaluation we arrive at an average concentration of nitrate in the CCN-range of $0.34 \mu \mathrm{g} \mathrm{m}^{-3}$. As mentioned above, with the CCN-range the aerosol smaller than $0.18 \mu \mathrm{m}$ is defined.

The concentrations of sulphate and chloride were also determined. The LOD for sulphate of $0.31 \mu \mathrm{g} \mathrm{m} \mathrm{m}^{-3}$ is substantially higher than that for nitrate. Accumulation of uncertainties results in a rather large uncertainty in the ratio of the two concentrations to be discussed in the next chapter. The most likely counter-ion of nitrate, ammonium, was also measured. Its LOD was too high to warrant analysis of the balance between cations and anions per measuring cycle. The uncertainty only allowed evaluation of the ion balance over the whole of the data set, which was unity within the error limit. It supports the hypothesis that nitrate in this size-range is present as ammonium nitrate.

It should be considered that the concentration of nitrate is a lower limit in view of the possibility of evaporation of the semi-volatile (ammonium) nitrate in the sample line that extended for some distance inside the meteo-tower. As mentioned before, temperatures inside were extreme, which lead to heating of the sampling line and possibly the sample-flow. Summarising, the amount of nitrate in the CCN-range reported here is a minimum-value.

The average concentration of chloride in the CCN-range was less than the lower detection limit of $0.03 \mu \mathrm{g} \mathrm{m}^{-3}$. This is a negligible value in comparison to that of the two other anions.

\section{General discussion}

We monitored the concentration of nitrate in the aerosol with an aerodynamic diameter smaller than $0.18 \mu \mathrm{m}$. The data encompass a period of two months in the summer of 2002. The number of data may seem limited, however it should be appreciated that the total number of 2-hour data points is over four hundred. This number of data is typically an order of magnitude higher than the number of samples collected in studies with classical manual cascade-impactor sampling. Moreover, representative data for the semi-volatile ammonium nitrate were obtained. This is especially important because the measurements were made at the elevated temperatures of summer, when collection artefacts with the classical samplers are highest.

The average mass concentration of nitrate in the aerosol smaller than $0.18 \mu \mathrm{m}$ was $0.34 \mu \mathrm{g} \mathrm{m}^{-3}$. To put this in perspective it should be compared with that that of sulphate in the same size-range, of which the time-evolution is depicted in Fig. 4. The concentration of sulphate, considered to be the prominent compound in the smallest aerosol in our region, was on average $0.53 \mu \mathrm{g} \mathrm{m}^{-3}$. This would imply that the ratio of the concentration of nitrate and sulphate in the given range is 0.6.

While a ratio of 0.6 in the concentration of nitrate to sulphate is high it should be considered that in this case all data were used. The ratio shows quite large scatter from one measuring cycle to the other (Fig. 5). The reason is that the values of sulphate are often close to the lower detection limit for this component. When we take this into account and only use the data from those periods during which the concentration of both sulphate and nitrate exceed the lower limit of detection by a factor of two, a different statistics for the ratio of the concentration of the two compounds arise. With dismissal of $30 \%$ of the data, the ratio of the concentrations of the two components is close to one. It should be considered that in this way a bias is generated in the data. This shows the need for improved sensitivity of the instrumentation, especially for sulphate.

We like to briefly discuss the diurnal course of the concentration of the smallest nitrate in the framework of the Indirect Aerosol Effect. The effect is in essence the modification of the reflection of sunlight by clouds and occurs during the daylight hours only. The aerosol present at that moment is of relevance. It had been expected that the concentration of the 
ug $\mathrm{m}^{-3}$

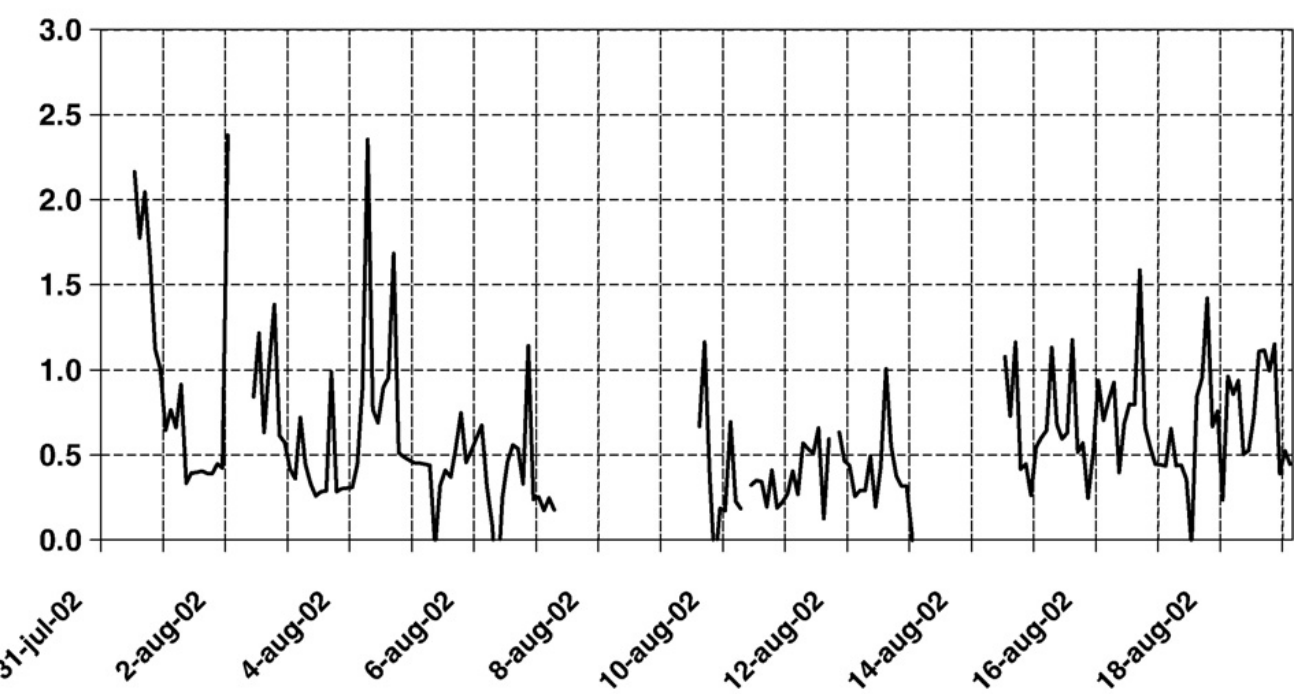

Fig. 4. The concentration of sulphate in the aerosol smaller than $0.18 \mu \mathrm{m}$ in diameter. The values are blank corrected. Other information can be found in the caption of Fig. 2.

semi-volatile nitrate would be low during daytime, because its vapour pressure is a function of temperature and relative humidity. Daytime conditions, with higher temperatures and lower relative humidities favour the existence of the gas phase, while at night the balance should be towards the aerosolphase. As discussed above, such a pattern would have been specifically expected for the smallest particles. The observations did not bear out this hypothesis. There are occasions, like at the end of the measuring campaign (Fig. 2), that the concentration peaks in the afternoon.

A possible reason for the absence of a diurnal variation, or in general the high concentrations of ammonium nitrate at daytime, is the high ammonia-concentrations. These high concentrations stabilise the ammonium nitrate in the aerosol- phase, even at the elevated temperatures encountered in this summer campaign. The issue, however, is much more complex because of horizontal and vertical transport of ammonium nitrate and precursors. Hopefully, then, the present rather unique data will become the subject of an analysis with detailed atmospheric chemistry modelling to search for a real explanation of the observations.

There might be a question on the need to analyse the composition of the $\mathrm{CCN}$ in view of the remarks in a recent paper that emphasised that the number of CCN is of more importance than composition for the number of cloud droplets (Dusek et al., 2006). This is a valid argument as such but less so in the frame of assessing the magnitude of the Indirect Aerosol Effect. Then the question is how many of the CCN are

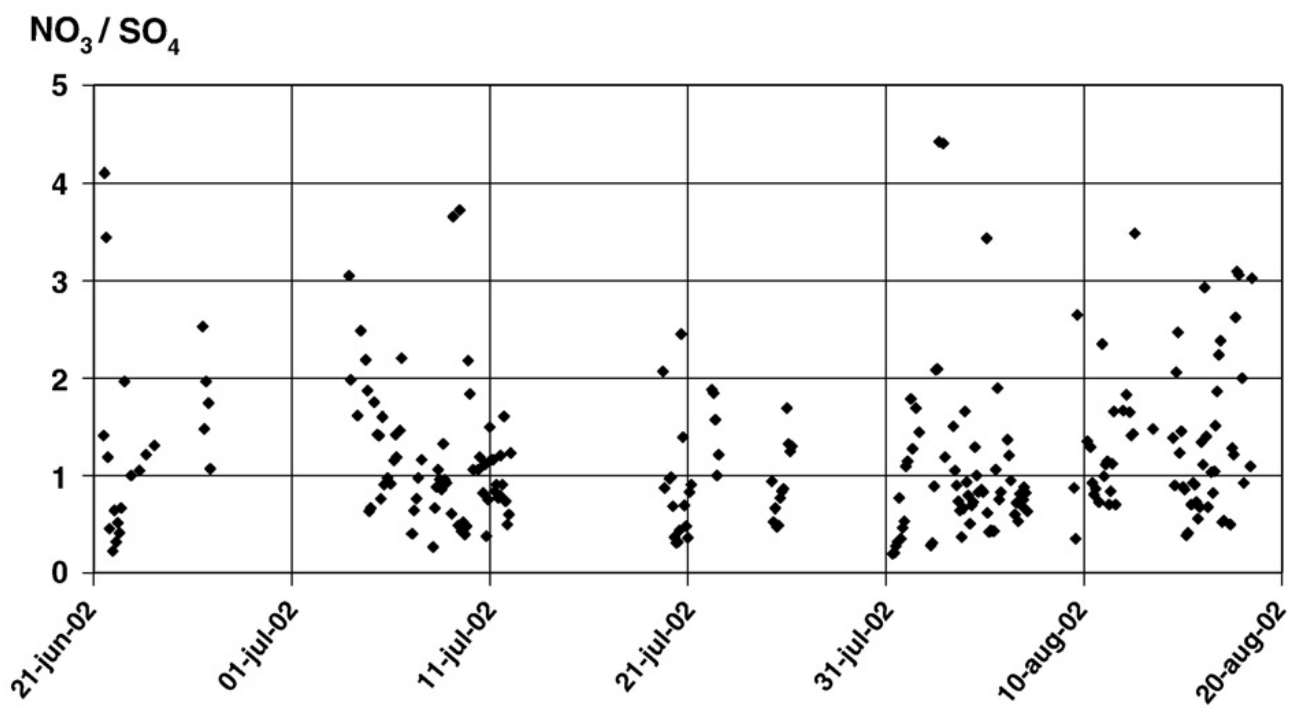

Fig. 5. The ratio of the mass concentration of nitrate to sulphate in aerosol smaller than $0.18 \mu \mathrm{m}$ in diameter. Data taken during the campaign described in Fig. 2 . Only those ratios are included for which the concentrations, especially those of sulphate, exceeded the lower detection limit; see text for further details. 
of a manmade origin. Also the trend in the regional IAE depends on the origin and thus composition of the manmade portion of the CCN. In view of the large uncertainties in the IAE also the information obtained on sulphate in the CCNrange present study might be of relevance for evaluation of models that describe the detailed time and size-resolved behaviour of the regional sulphate. A key finding in this respect is the absence of a diurnal variation in the concentration of sulphate in the CCN-range.

\section{Conclusions}

A new instrument, the "MARGA-sizer", for representative monitoring of the concentration of nitrate in size-segregated aerosol was developed. It also determines sulphate.

The MARGA-sizer was deployed in a summer campaign at the CESAR-site of Cabauw, in the centre of the Netherlands. The overall ratio of nitrate to sulphate in the aerosol smaller than $0.18 \mu \mathrm{m}$ in diameter was 0.6 . When only data-points are considered for which the concentrations of both components exceed the lower limit of detection, the ratio in the smallest size-fraction is close to unity.

A major part of the cloud nuclei resides in the indicated size-fraction in our region and it can be speculated that nitrate plays part in the regional cloud formation. However, assessment of the actual importance of nitrate requires additional research.

Contrary to expectations, no significant diurnal variation in the concentration of the nitrate in the smallest size fraction was observed. For sulphate there was also no systematic difference in the day-time and night-time concentrations.

The low concentrations in the smallest aerosol fraction, relative to the Lower Detection Limit of the instrumentation, calls for improved sensitivity.

\section{Acknowledgements}

The study was performed within the framework of the Dutch Climate Change and Spatial Planning program BSIKKlimaat voor Ruimte and supported by the ministry of Housing, Spatial Planning and the Environment (VROM). Parts of the results were presented at the European Aerosol Conference of 2005 and the International Aerosol Conference of 2006 and are available as abstract in the respective proceedings.

\section{References}

Allen, A.G., Harrison, R.M., Erisman, J.W., 1989. Field measurements of the dissociation of ammonium nitrate and ammonium chloride aerosols. Atmos. Environ. 23, 1591-1599.

Arends, B.G., Baard, J.H., ten Brink, H.M., 1997. Trends in summer sulphate in Europe. Atmos. Environ. 31, 4063-4072.

Bondietti, E.A., Papastefanou, C., 1989. Large particle nitrate artifacts in the aerodynamic size distributions of ambient aerosols. J. Aerosol Sci. 20, 667-670.
Chang, M.C., Sioutas, C., Fokkens, P.B., Cassee, F.R., 2001. Field evaluation of a mobile high-capacity particle size classifier for coarse, fine and ultrafine particles. J. Aerosol Sci. 32, 139-156.

Dusek, U., Frank, G.P., Hildebrandt, L., Curtius, J., Schneider, J., Walter, S., Chand, D., Drewnick, F., Hings, S., Jung, D., Borrmann, S., Andreae, M.O., 2006. Size matters more than chemistry for cloud-nucleating ability of aerosol particles. Science 312, 1375-1378.

Forster, P., Ramaswamy, V., Artaxo, P., Berntsen, T., Betts, R., Fahey, D.W. Haywood, J., Lean, J., Lowe, D.C., Myhre, G., Nganga, J., Prinn, R., Raga, G., Schulz, M., Van Dorland, R., 2007. Changes in atmospheric constituents and in radiative forcing. In: Solomon, S., Qin, D., Manning, M., Chen, Z., Marquis, M., Averyt, K.B., Tignor, M., Miller, H.L. (Eds.), Climate Change 2007: The Physical Science Basis. Contribution of Working Group I to the Fourth Assessment Report of the Intergovernmental Panel on Climate Change. Cambridge University Press, Cambridge, United Kingdom.

Herrmann, H., B rüggemann, E., Franck, U., Gnauk, T., Löschau, G., Müller, K., Plewka, A., Spindler, G., 2006. A source study of PM in Saxony by sizesegregated characterisation. J. Atmos. Chem. 55, 103-130.

Khlystov, A. 1998. Cloud forming properties of ambient aerosol in the Netherlands. PhD thesis, University of Wageningen.

Khlystov, A., Kos, G.P.A., ten Brink, H.M., Kruisz, C., Berner, A., 1997a. Activation properties of ambient aerosol in The Netherlands. Atmos. Environ. 30, 3281-3290.

Khlystov, A., Even, A., ten Brink, H.M., 1997b. Effect of temperature, ammonia concentration and flow rate on under-sizing of ammonium nitrate aerosol in DMPS/SMPS. J. Aerosol Sci. 28, S59-S60.

Martin, G.M., Johnson, D.W., Spice, A., 1994. The measurement and parameterization of effective radius of droplets in warm stratiform clouds. J. Atmos. Sci. 51, 1823-1842.

Matta, E., Facchini, M.C., Decesari, S., Mircea, M., Cavalli, F., Fuzzi, S., Putaud, J.-P., Dell'Acqua, A., 2003. Mass closure on the chemical species in sizesegregated atmospheric aerosol collected in an urban area of the Po Valley, Italy. Atmos. Chem. Phys. 3, 623-637.

Mikuska, P., Even, A., Khlystov, A., ten Brink, H.M., Slanina, J., 1997. Artefactfree method for size-resolved chemical analysis of ambient aerosols. J. Aerosol Sci. 28, S443-S444.

Penner, J.E., Andreae, M., Annegarn, H., Barrie, L., Feichter, J., Hegg, D. Jayaraman, A., Leaitch, R., Murphy, D., Nganga, J., Pitari, G., 2001. Aerosols, their Direct and Indirect Effects; Chapter 5 in Climate Change 2001: the scientific basis. Cambridge University Press.

Putaud, J.-P., Van Dingenen, R., Dell'Acqua, A., Raes, F., Matta, E., Decesari, S. Facchini, M.C., Fuzzi, S., 2004. Size-segregated aerosol mass closure and chemical composition in Monte Cimone (I) during MINATROC. Atmos. Chem. Phys. 4, 889-912.

Raga, G.B., Jonas, P.R., 1993. On the link between cloud-top radiative properties and sub-cloud aerosol concentrations. Q. J. R. Meteorol. Soc. 119 , 1419-1425.

Sellegri, K., Laj, P., Peron, F., Dupuy, R., Legrand, M., Preunkert, S., Putaud, J.P., Cachier, H., Ghermandi, G., 2003a. Mass balance of free tropospheric aerosol at the Puy de Dome (France) in winter. J. Geophys. Res. 108 (D11), 4333. doi:10.1029/2002JD002747.

Sellegri, K., Laj, P., Dupuy, R., Legrand, M., Preunkert, S., Putaud, J.P., 2003b. Size dependent scavenging efficiencies of multi-component atmospheric aerosols. J. Geophys. Res. 108 (D11), 4334. doi:10.1029/2002JD002749.

Slanina, J., ten Brink, H.M., Otjes, R.P., Even, A., Jongejan, P., Khlystov, A., WaijersIJpelaan, A., Hu, M., Lu, Y., 2001. Continuous analysis of nitrate and ammonium in aerosols by the Steam Jet Aerosol Collector (SJAC): extension and Validation of the Methodology. Atmos. Environ. 35, 2319-2330.

ten Brink, H.M., Kruisz, C., Kos, G.P.A., Berner, A., 1997. Size/composition of the light-scattering aerosol in The Netherlands. Atmos. Environ. 31, 3955-3962.

ten Brink, H.M., Otjes, R., Jongejan, P., Slanina, J., 2007. An instrument for semi-continuous monitoring of the size-distribution of ammonium nitrate aerosol. Atmos. Environ. 41, 2768-2779.

Trebs, I., Meixner, F.X., Slanina, J., Otjes, R., Jongejan, P., Andreae, M.O., 2004. Real-time measurements of ammonia, acidic trace gases and watersoluble inorganic aerosol species at a rural site in the Amazon Basin. Atmos. Chem. Phys. 4, 967-987. 